\title{
Zapatismo, \\ una grieta en el muro
}

\section{ANA LILIA FÉLIX PICHARDO*}

* Estudiante

de la Unidad

Académica de

Letras, Universidad

Autónoma de

Zacatecas

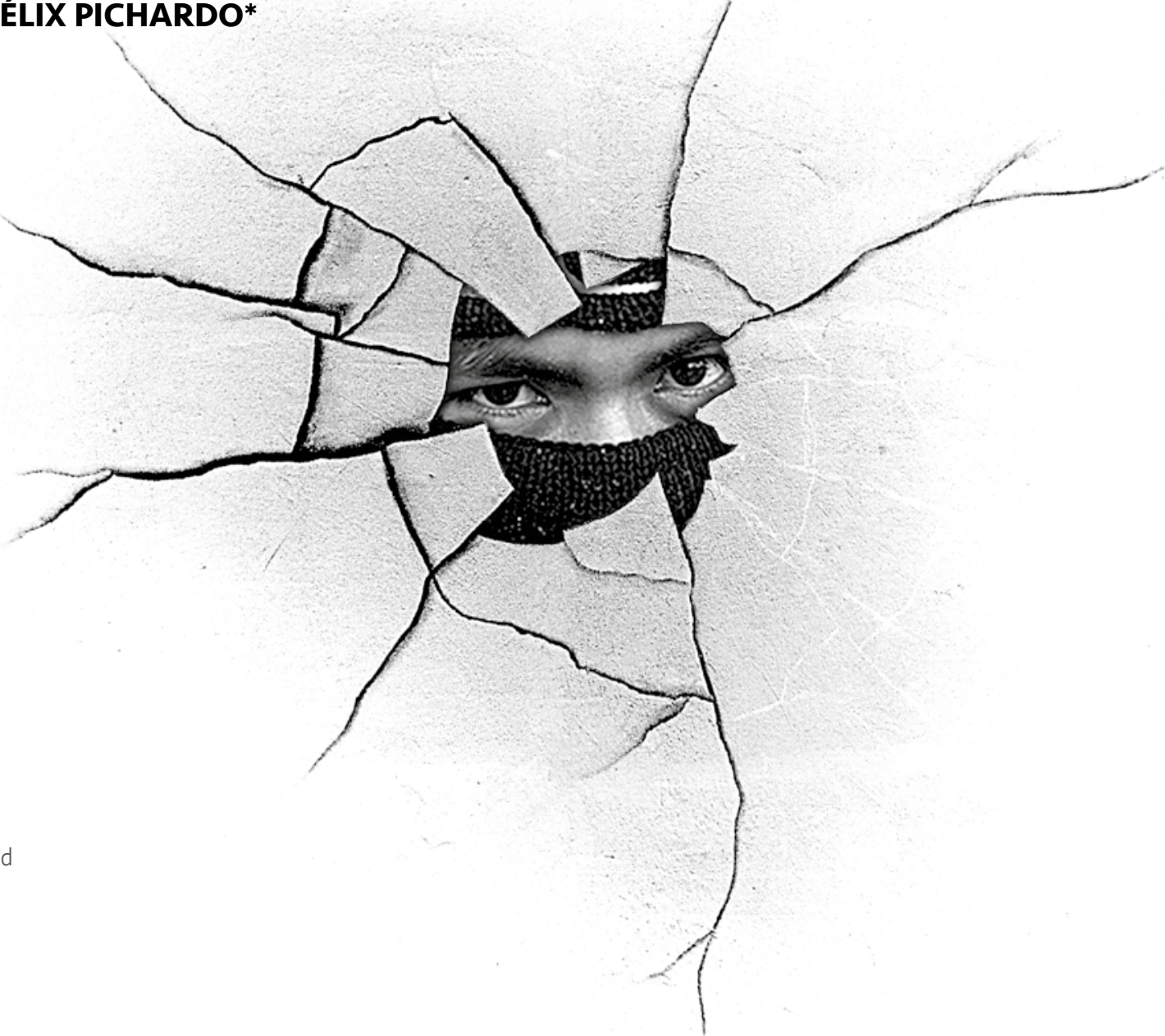

Los zapatistas devienen de comunidades indígenas despojadas de tierras y de la libertad para gobernarse según la cultura de los pueblos originarios; producto de su organización y lucha lograron formar comunidades organizadas en gobiernos autónomos. Cuentan con una caja de herramientas provista de conceptos teóricos y trabajo colectivo que se usan como armas para analizar las entrañas del capitalismo, impulsar la resistencia política y construir la autonomía de los pueblos rebeldes. Ahora sus palabras resuenan con el propósito de reivindicar la autonomía que erigieron al fragor de su gesta social y de advertir sobre la inminencia de la crisis capitalista y los múltiples peligros que representa la Hidra para los pueblos y las organizaciones que se aprestan a luchar. 
El zapatismo se ha explicado al exterior de manera simultánea al ejercicio de su lucha e iniciativas políticas. En El pensamiento crítico frente a la Hidra capitalista I hay tres apartados principales que facilitan la comprensión de la resistencia de los pueblos zapatistas durante más de veinte años. Hacen un recorrido histórico que muestra cómo las comunidades indígenas de la zona de Chiapas fueron despojadas de sus tierras y de su libertad para gobernarse según la cultura de los pueblos originarios.

Las palabras zapatistas contrastan la realidad previa al alzamiento con la construida en las comunidades gracias a los gobiernos autónomos. Desde su perspectiva los comandantes del Ejército Zapatista de Liberación Nacional (EZLN) avisan sobre la crisis que se avecina producto de la evolución del capitalismo, muestran cómo la autonomía se ha consolidado sobre los pilares de la rebeldía y la resistencia, y hablan del peligro inminente que representa la adaptación constante de la Hidra ante las condiciones de lucha de los pueblos y las organizaciones.

También la advertencia es una alternativa, ya que el profundo análisis que hacen del capitalismo es desde la resistencia política que ha engendrado la autonomía de los pueblos rebeldes. Lo valioso de la interpretación de la realidad y del sistema económico, compartido por los zapatistas, radica en que es producto de la teoría y la práctica que llevan a cabo en la cotidianeidad de su propia lucha frente al sistema-muro.

Desde la praxis nace la reflexión en torno a ese quehacer revolucionario y sobre el desarrollo de los mecanismos de destrucción que el capitalismo está echando a andar. Además, el pensamiento zapatista es una práctica en sí misma, porque de ella nace, e increpa a hombres y mujeres para que se pregunten, pero sobre todo se respondan, cómo su acción contribuye con la caída del muro, con la muerte definitiva de la Hidra.

El zapatismo acepta que no es un fenómeno lejos del alcance de la ciencia de la historia, por el contrario: explica que para entenderse de una mejor manera ha recurrido a los conceptos teóricos de la economía política como otra de sus herramientas de lucha.

$\mathrm{Al}$ igual que las armas y el trabajo colectivo, la ciencia representa un instrumento de la resistencia: «Para lo que tenemos que hacer necesitamos herramientas, y esas herramientas son conceptos teóricos». ${ }^{1}$ A fin de conseguir la construcción permanente de la autonomía y la revisión de cómo las estrategias puestas en marcha han funcionado o no a las comunidades, el zapatismo se desplaza, entre la teoría y la práctica.

El método zapatista de lucha se puede encontrar en la dialéctica de su pensamiento y su praxis, tal como lo ejemplifica al compartir la historia de su propia genealogía, donde los logros no pocas veces van acompañados de contradicciones y problemáticas al interior, que se han tenido que subsanar. En el ejercicio de la autonomía se ha descubierto la forma de mejorar y no retroceder a un estado de cosas anterior. El fundamento del gobierno autónomo son los pueblos, que respaldan el ejercicio de la administración a partir del principio del «mandar obedeciendo» y le dan sentido a la organización y la lucha zapatista: «No vamos a tenerle miedo al pueblo, a plantearle, por muy difícil que sea, nuestras propuestas». ${ }^{2}$

La narratividad de la resistencia desempeña un papel vital en la fijación del pensamiento político de los zapatistas. Pese a que la realidad en las comunidades en resistencia se configura en múltiples lenguas originarias, la narración literaria de la lucha al exterior cumple con una función cohesionadora del imaginario colectivo de los pueblos rebeldes. Por ello, en la construcción de los personajes protagonistas de las historias, también hay una cimentación del cómo

${ }^{1}$ Subcomandante insurgente Galeano, El pensamiento critico frente a la Hidra capitalista I. Participación de la comisión sexta del EZLN, Chiapas, EZLN, 2015, p. 353.

${ }^{2}$ Subcomandante insurgente Moisés, El pensamiento crítico frente a la Hidra capitalista I. Participación de la comisión sexta del EZLN, Chiapas, EZLN, 2015, p. 175. 
se están viendo los zapatistas a sí mismos en los símbolos culturales. La narración del propio zapatismo evidencia una liberación de los imaginarios y el nacimiento de nuevas estructuras culturales nacidas dentro de la lucha de los pueblos originarios contra el sistema capitalista. A la vez, la recreación de la lucha a través de las artes refiere la capacidad de la resistencia zapatista para transgredir más allá de la materialidad del día a día, hasta el terreno de las subjetividades.

\section{Desde la autonomía, con rebeldía y resistencia}

La base del nacimiento de la autonomía ha sido el trabajo. Luego del proceso de recuperación de tierras a partir del levantamiento armado en 1994, comienza una reorganización comunitaria respecto al trabajo agrícola y ganadero. Después de que el Senado aprueba una Ley de Derecho Indígena y Cultura opuesta a los acuerdos emanados de las mesas de diálogo de San Andrés, los pueblos zapatistas no esperaron el consentimiento de los gobiernos para fincar la autonomía sobre la resistencia económica: «No vamos a pedirle permiso a nadie, ya para nosotros se acabó eso de que no nos reconocieron la Ley sobre Derechos y Cultura Indígena». ${ }^{3}$ La autodeterminación democrática aprende a distanciarse de los tiempos y formas de la contienda militar:

En lo militar las órdenes se cumplen, no se discuten, no hay democracia, entonces como así lo preparamos los compañeros milicianos y milicianas por eso entonces pudimos controlar los miles de combatientes, porque funcionó lo que es orden que no se discute, pero a la hora de construir la autonomía nos costó mucho para quitar en la cabeza que el gobernar no se maneja órdenes, ahí se maneja acuerdos. ${ }^{4}$

${ }^{3}$ Ibid., p. 149.

${ }^{4}$ Ibid., p. 161.
Ponen en manos del colectivo la toma de decisiones y se confía en su mandato, de modo que se ejercen los siete principios del mando obediencial, se trata de otra forma de hacer política. Los trabajos colectivos son el fundamento de la organización, pues permiten el ejercicio autónomo y el fortalecimiento de la lucha. Lo obtenido de la colectividad se administra de manera que se satisfagan las necesidades de subsistencia y se continúe resistiendo contra la guerra de baja intensidad implementada contra los pueblos:

Una de las bases de lo que es nuestra resistencia económica, nosotros, nosotras las zapatistas, es la madre tierra (...), tenemos salud, tenemos educación, estamos en eso que son los pueblos los que mandan y los gobiernos obedecen. 5

Como herramientas colectivas de la lucha zapatista, la rebeldía y la resistencia han permitido la materialización de la libertad y la justicia en el territorio liberado. La educación, salud y justicia autónoma se erigen por los recursos que la colectividad les destina; obedecen a los principios políticos de la organización, pues significan la herencia que los pueblos están legando a las generaciones futuras: «Tienen que estar preparándose las generaciones para que nunca jamás vuelva el nieto de Absalón Castellanos Domínguez, o Javier Solórzano, uno de los grandes finqueros pues». ${ }^{6}$ La apuesta del zapatismo es por la posibilidad de nuevas relaciones sociales, fuera de la dominación y la explotación patriarcal

${ }^{5}$ Ibid., p. 92.

${ }^{6}$ Ibid., p. 148. 
de los finqueros, los hacendados y los malos gobiernos.

El control colectivo de los medios de producción ha empoderado a las comunidades para llevar a cabo las tareas de educación, salud y justicia. Las escuelas y los hospitales se construyen con el trabajo de los pueblos, quienes también deciden de manera democrática hacia dónde dirigir los recursos obtenidos de la comunidad, la región, el municipio o la zona.

Si bien los pueblos tienen la libertad de tomar decisiones según las necesidades particulares de su territorio, las Juntas de Buen Gobierno facilitan la coordinación entre las zonas e igualan los proyectos en cada región para evitar el avance desproporcionado: «Los MAREZ estaban sueltos (...) entonces cuando la Junta de Buen Gobierno ya se forma empieza a controlar los municipios para que sea parejo, igual los proyectos». ${ }^{7} \mathrm{El}$ intercambio de mercancías o de tiempo de trabajo al interior de las comunidades ha sustituido en gran medida el uso de dinero: «Pocas veces manejamos dinero (...), en la movilización ahí sí nos obliga, porque hay que pagar con pesos la gasolina, no nos acepta kilos de maíz, frijol». ${ }^{8} \mathrm{Al}$ no depender la economía interna del pago de patrones, lo que existe es el fruto del trabajo colectivo. Con ello la transformación de las relaciones interpersonales también está regida por nuevos paradigmas, no ya los de la explotación y el dominio.

La legalidad emanada del Estado de derecho mexicano no sólo no ha ofrecido justicia para los pueblos originarios, sino que es el arma utilizada por los latifundistas, los malos gobiernos y las empresas para legitimar el

${ }^{7}$ Ibid., p. 149.

${ }^{8}$ Ibid., p. 98. despojo y desmantelamiento del territorio de los pueblos indígenas. Nunca en las leyes han encontrado los pueblos originarios la respuesta a sus demandas, porque por siglos no fueron siquiera considerados sujetos de derecho en el país, desde la conquista. Por el contrario, las leyes respaldan los intereses de quienes buscan apropiarse de la tierra y sus recursos y mercantilizar todo el proceso de despojo. La traición consumada contra los pueblos originarios corroboró que desde la legalidad de un Estado, sometido a las normas del sistema, jamás habrá justicia para los desposeídos. El levantamiento armado conmocionó a una sociedad y un Estado de derecho etnocentrista, que deliberadamente ignora a la población originaria, negándoles su derecho a la vida y a la tierra. La firma de los Acuerdos de San Andrés significó un hecho sin precedentes en un país como México, que durante su historia intentó la homogeneización cultural, pensada en torno a los valores de Occidente.

A partir de la resistencia ha surgido una forma «muy otra» de impartir justicia en territorio zapatista. Los conflictos o situaciones cotidianas se resuelven mediante los principios democráticos de la organización, de esa manera se pretende subsanar las problemáticas de manera pacífica. La reconciliación entre las partes es el objetivo de la justicia autónoma, ya que en la colectividad, como núcleo de las relaciones sociales, es donde se pueden solucionar las situaciones que ponen en riesgo los vínculos armoniosos que sustentan la cohesión comunitaria. No sólo se ofrece la justicia a los miembros de la organización, sino que indígenas no zapatistas acuden a las instancias del gobierno autónomo en búsqueda de una justicia que no llega de un sistema burocrático y etnocéntrico:

El trabajo que hacen las autoridades de la justicia también es un servicio gratuito, incluyendo sus resultados, lo cual quiere decir que la justicia no 

se cobra, ni a los que no son zapatistas, y ésta es una de las razones por las que mucha gente prefiere esta alternativa. $^{9}$

En el discurso oficial los indígenas son automáticamente infractores de la ley y enemigos del Estado, razón por la cual no se les brindan las herramientas para una defensa justa en casos de infracciones a la ley. Por el contrario, los usos tradicionales de los pueblos indios para dirimir sus conflictos quedan anulados ante el sistema penal mexicano, que no otorga siquiera las condiciones para la traducción de sentencias a las lenguas indígenas, marginando de facto a los pueblos originarios de la justicia.

\section{La Hidra y el muro}

La Hidra y el muro, metáforas que representan el capitalismo, permiten la asequibilidad de un sistema paradójicamente sin rostro, pero con múltiples cabezas. La crítica al relativismo social y la renuncia en la posmodernidad a la ciencia de la historia llevan al método zapatista a incursionar en el origen del sistema, pues sólo conociendo al monstruo se sabrá cómo darle muerte: «Necesitamos del pensamiento crítico para mantener en crisis constante, es decir, en movimiento, nuestro conocimiento de la Hidra». ${ }^{10}$

El pensamiento crítico es entendido como teoría y práctica, a su vez herramientas de la lucha colectiva contra el sistema muro. Las mutaciones de la Hidra exigen un conocimiento permanente de su naturaleza, su origen y sus cambios, como punto de partida para la organización de la rebeldía y la resistencia. Es decir que para el zapatismo, las ciencias son herramientas indeleznables para la lucha, fundamentales para el conocimiento de la realidad, el análisis pro-

${ }^{9}$ Paulina Fernández Christilieb, Justicia autónoma zapatista, zona selva Tzeltal, México, Ediciones Autónom@s, 2014, p. 213.

${ }^{10}$ Subcomandante insurgente Galeano, op. cit., p. 285. fundo de ésta y su transformación.

La resistencia para los pueblos originarios, «sótanos del mundo», es inherente. Que una tormenta catastrófica se aproxima con rapidez, es la conclusión a la que llega el método de investigación zapatista. Luego de su observación, análisis y resistencia contra la Hidra, los zapatistas reconocen signos anormales, agudización de ciertos síntomas que hablan de la enfermedad del monstruo, que no por enfermo puede estar agonizante. Sin embargo, es debido a la necesidad de sobrevivir a la crisis que avistan, que el conocimiento de la genealogía y evolución del sistema se hace elemental para cruzar los caminos de la rebeldía y la resistencia en las geografías y calendarios de abajo. El tiempo de la lucha de los pueblos anclado en el devenir histórico busca enlazar a las generaciones futuras con el conocimiento heredado por los antiguos hombres y mujeres que teorizaron sobre el sistema e intentaron derribar el muro.

Aquella tesis de la llegada de una tormenta brutal se sustenta precisamente en el conocimiento del sistema en su nacimiento y desarrollo: «En nuestra historia, la lección se repite una y otra vez. Y en cada vuelta del mundo, siempre es para nosotros el lugar del oprimido, del despreciado, del explotado, del despojado». ${ }^{11} \mathrm{La}$ guerra, motor principal de la Hidra, acelera su paso para la obtención de mayor número de ganancias, a base del despojo y la destrucción de los territorios:

Las que llamamos las «4 ruedas del capitalismo»: explotación, despojo, represión y desprecio, se han repetido a lo largo de toda nuestra historia, con diferentes nombres arriba, pero nosotros somos siempre los mismos abajo. ${ }^{12}$

Es también la guerra la respuesta del ca-

${ }^{11}$ Subcomandante insurgente Marcos, Ellos y nosotros. V. La Sexta, Chiapas, enero de 2013, http://enlacezapatista.ezln. org.mx/2013/01/26/ellos-y-nosotros-v-la-sexta/ ${ }^{12}$ Idem. 
pitalismo a las crisis nacidas del insostenible divorcio entre la producción y la especulación. El fundamento mismo del capital financiero encarna una contradicción en sí mismo. En búsqueda de ganancias que respalden la ficción de capital se libra una batalla contra la humanidad entera, en el proceso de reordenamiento que pretende la mercantilización de territorios y personas. Los recursos naturales de los países están hipotecados al capital financiero a raíz de las deudas de las naciones, por lo cual los mecanismos del despojo se enfrentarán a la resistencia organizada de los habitantes del mundo. La renuncia al pensamiento crítico, a la ciencia como herramienta de lucha y el evidente pensamiento haragán entre los investigadores de las ciencias sociales son también para los zapatistas signos inequívocos de la tormenta:

Si hay quien piensa que todo sigue igual y que con elecciones, marchas, tuiters, firmas en change.org o no sé cómo madres se diga, van a cambiar las cosas, pues no van a cambiar. Tenemos que buscar otras formas. ¿Para qué? Bueno, es ¿para qué?, es el que tenemos que responder y tenemos que volver a dibujar la cara de la Hidra porque cambió. ${ }^{13}$

El éxito de las filosofías posmodernas que, como productos asequibles para las masas, surgen como cabeza de la Hidra, es resultado de la promoción mediática que ha hecho el sistema para promocionar, vía academias científicas, el fin de la historia. No sólo no renuncia el zapatismo a los conceptos teóricos, sino que desde ellos se explica a sí mismo y emprende nuevas estrategias de lucha contra el capitalismo. Teóricamente se explica la realidad inmediata: que dentro de poco, 40 por ciento de la población mundial se habrá convertido en migrante; que la injerencia de los gobiernos se limita ahora al control de la fuerza pública al servicio del capital; que el despojo y la explotación tengan

${ }^{13}$ Subcomandante insurgente Galeano, op. cit., p. 354. el rostro amable del progreso. Esos síntomas anuncian la inminente tormenta, ante la cual, para sobrevivir, habrá que estar organizados en colectivo: «Nosotras y nosotros los zapatistas les decimos por experiencia, se necesita ORGANIZACIÓN, trabajo y lucha, esfuerzo y sacrificio, resistencia y rebeldía». ${ }^{14}$

\section{«Falta lo que falta»}

Desde una geografía y un calendario abstraídos del tiempo de dominación capitalista, el zapatismo comparte su diagnóstico sobre la Hidra y sus nuevos rostros, pero también permite un acercamiento a la resistencia de las comunidades. En su propia práctica teórica sobre la organización política, los zapatistas muestran un proceso de lucha construido en el diario resistir de las comunidades insertas en una lógica muy diferente a la propuesta por el capitalismo. El mando del pueblo y la obediencia de las autoridades autónomas sugieren que es posible la construcción de relaciones sociales opuestas a la explotación sistémica.

Una democracia verdadera indudablemente acompaña un modelo de impartición de justicia, en el cual hay una reparación y reconciliación comunitaria, sean o no zapatistas las partes involucradas. En colectivo, la organización ha engendrado la autonomía; ha creado opciones y permitido la vida en lugar de la muerte, ofertada por el mal gobierno; ha heredado la rebeldía y resistencia para los que vendrán a seguir peleando; ha hecho tangible la libertad y la justicia para los pueblos originarios de México.

La alternativa política del zapatismo se ha enfrentado al sistema, al construir desde la autonomía alternativas de vida en comunidad. En voz de los altos mandos del EzLN, la alerta que mandan las bases de apoyo zapatista es máxima: está en riesgo no sólo la organización de los pueblos en resistencia, sino la vida entera de la hu-

\footnotetext{
${ }^{14}$ Subcomandante insurgente Moisés, op. cit., p. 366.
} 
manidad y la naturaleza; por ello es apremiante organizar la rebeldía y comenzar a construir barricadas ante la guerra cruel que se avecina. Según opinión del zapatismo, nacida de la experiencia, es posible vivir de manera anticapitalista; con la resistencia se pueden construir nuevas formas de relaciones sociales y la vía para ello es la colectividad. El conocimiento de su propio quehacer, de sus aciertos y desaciertos ha nacido de la lucha y reflexión colectiva de los pueblos: «La lucha, la pelea, no sólo nomás es con las armas, sino también es en lo político, en lo ideológico y en lo económico y lo demás». ${ }^{15}$ Entenderse en el otro, que es espejo de sí mismo, ha permitido que la fuerza de la comunidad moldee la realidad conforme a cómo los zapatistas la imaginan y sueñan.

El zapatismo ha reconocido las múltiples cabezas de la Hidra y de ese reconocimiento del enemigo es que se articulan las luchas al interior de los caracoles. La base de la resistencia es económica; si el capital financiero pretende la mercantilización de la vida y el territorio, el zapatismo ofrece una nueva forma de establecer relaciones económicas entre las bases de apoyo y los indígenas no zapatistas con quienes conviven: «Ya antes lo hemos dicho, pero ahora lo recuerdo: Nuestra rebeldía es nuestro $\langle\mathrm{NO}\rangle$ al sistema. Nuestra resistencia es nuestro 〈SÍ> a otra cosa es posible». ${ }^{16}$ La autonomía política también ha permitido que la imaginación de mundos posibles se materialice en la realidad y en la ficción de los imaginarios

Con nuestra resistencia y rebeldía que nos ha dado la libertad para crear, inventar, imaginar de cómo trabajar mejor nuestro gobernar para tener una mejor vida, y eso es lo que nos está ayudando de ir descubriendo de cómo mejorar el gobernar o su trabajo de nuestros gobiernos autónomos. ${ }^{17}$

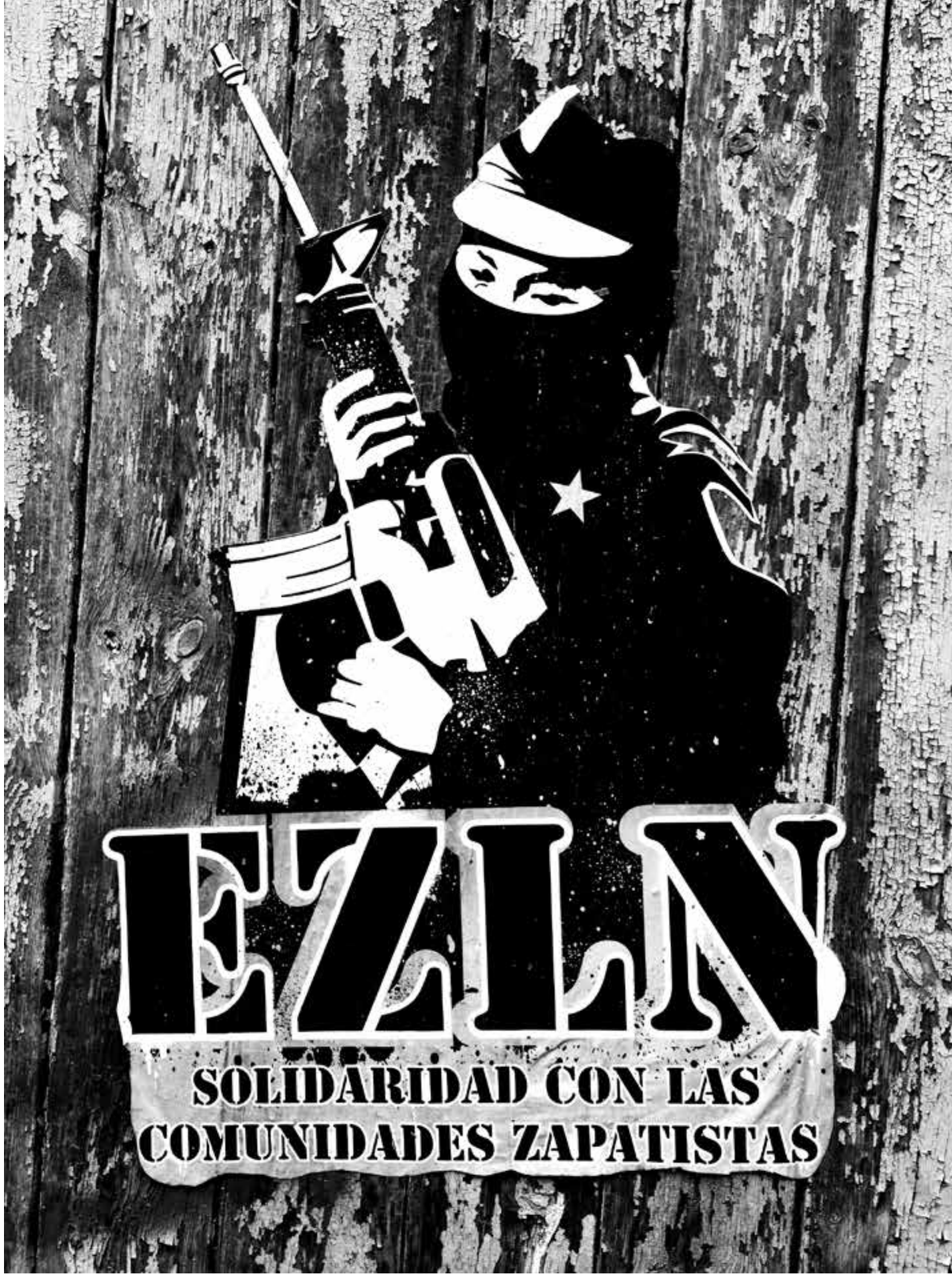

El arte representa una arma de gran valor para los pueblos zapatistas; el espíritu de la libertad deambula entre las manifestaciones literarias, musicales, pictóricas, de los hombres y mujeres zapatistas. La cultura ha sido revolucionada por la potente irrupción de la lucha anticapitalista, y es en el día a día que es posible palpar cómo los pueblos son libres por dentro y por fuera.
«La lucha, la pelea, no sólo nomás es con las armas, sino también es en lo político, en lo ideológico y en lo económico y lo demás».

\footnotetext{
${ }^{15}$ Ibid., p. 177.

${ }^{16}$ Subcomandante insurgente Galeano, op. cit., p. 221.

${ }^{17}$ Subcomandante insurgente Moisés, op. cit., p. 158.
} 